\title{
MEASURING CO-MOVEMENT OF REAL INTEREST RATE AND INFLATION RATE: USING VEC APPROACH
}

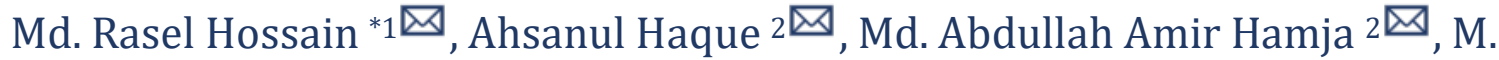 \\ Shohel Rana ${ }^{1 凶}$ \\ ${ }^{1}$ Department of Statistics, Noakhali Science and Technology University, Bangladesh \\ 2 Department of Statistics, Islamic University, Kushtia, Bangladesh
}

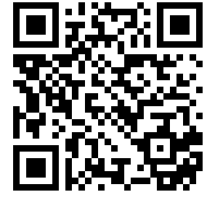

DOI: https://doi.org/10.29121/ijetmr.v7.i6.2020.687

Article Citation: Md. Rasel Hossain, Ahsanul Haqu, Md. Abdullah Amir Hamja, and M. Shohel Rana. (2020). MEASURING CO-MOVEMENT OF REAL INTEREST RATE AND INFLATION RATE: USING VEC APPROACH. International Journal of Engineering Technologies and Management Research, 7(6), 66-76. https://doi.org/10.29121/ijetmr.v7 .i6.2020.687

Published Date: 15 June 2020

Keywords:

VEC Models

Model Selection

Model Evaluation

\section{ABSTRACT}

It is important to know the future movement of economic variables for the planning and development of a country, Vector Error Correction (VEC) Model has been applied to disclose hidden long run as well as short-run patterns of the selected variables. ADF unit root testing procedure was applied to satisfy the conditions of applying the VEC Model. Using Johansen cointegration test long-run cointegration has been justified. But the VEC model reveals that long run significant causal relationship between the variables whereas there is no short-run causal relationship. The parameter was estimated using the OLS estimation technique. The validity of the model was confirmed by applying different quantitative approaches such as normality test, autocorrelation test, Portmanteau test, Unit root test, and various graphical approaches which suggested model selection and estimation were correct. The result of this present study may help Govt. agencies as well as planners to take an idea.

\section{INTRODUCTION}

\subsection{BACKGROUND OF THE STUDY}

The inflation rate and the interest rate are the most important and key factors in the Bangladesh economy. These factors and investigation of their relationships help to understand Bangladesh's economy more accurately and it is very useful to forecast these two variables for various issues of Bangladesh. The study is about an investigation of the relationship between the inflation rate and the interest rate based on the past data collected from the World Bank (WB) and quantifying the co-movement of these variables in the perspective of Bangladesh.

Time series modeling especially Vector Auto Regression (VAR) is an effective tool to reveal the past and future movement of several interrelated economic variables. This specific study is very important for the inquiry of the connection between Real Interest Rat and Inflation Rate. Also, very important for predicting these Real Interest Rat and Inflation Rate for the future in the context of Bangladesh. The data are collected from the World Bank for different analyses.

There are a few projects conducts on the relationship between the interest rate and inflation rate. But a little has been done in the situation of Bangladesh. It is well known that there is an obvious relationship or connection between those two variables. Be that as it may, the degree which one influences the other for various periods of time

(C) 2020 The Author(s). This is an open access article distributed under the terms of the Creative Commons Attribution License, which permits unrestricted use, distribution, and reproduction in any medium, provided the original author and source are credited. 
Md. Rasel Hossain, Ahsanul Haqu, Md. Abdullah Amir Hamja, and M. Shohel Rana

isn't certain. According to Fisher hypothesis of Irving Fisher introduced in 1930, the nominal interest rate is the sum of the constant real rate and the probable decline in the purchasing power of money.

From Fisher to the present time, this apparently simple hypothesis has got limited empirical support. In fact, Fisher hypothesis, hypothesizes that the nominal interest rate (Rt) may be taken to be the sum of the real rate of interest (Pt), which presents the relationship between the expected inflation and interest rates. Again, the inflation rate can likewise be predicted by the public (Пt). It is also shown a positive relationship between those two variables (Research Department, National Bank of Poland). Some of the previous studies have shown that in Bangladesh, the Fisher hypothesis is true. Also, between the variables there is a long run relationship.

\subsection{PROBLEMS AND MOTIVATIONS}

Inflation and Interest rates are two important factors in the Bangladesh economy. Previous works on these two variables are used but this study's most important concern is given to the investigation of the relation between these two important economic variables of Bangladesh one is the interest rate and the other is the inflation rate.

Since Fisher Hypothesis showed a relationship between the inflation and the interest rates, we make a proper prediction of interest rate and the inflation rate of Bangladesh. It is also necessary to see the relation is either the short run or the long run.

\subsection{OBJECTIVE OF THE STUDY}

It is important to identify goals and objectives early in the vulnerability assessment process as they help determine the level of detail required in the analysis and the data and products that might be needed.

The main purposes of the study are:

- To analyze the movement of economic variables of Bangladesh inflation rate and interest rate.

- To select an appropriate VAR model for our selected variables.

- To identify the co-integration relation between these two variables.

- To observe the linkage between RIR and IR

\subsection{LIMITATIONS OF THE STUDY}

The limitations of the study are:

- The data used in making the project report are secondary data.

- The resulting outputs are taken in two-three decimal places.

\subsection{COMPUTATIONAL ISSUE}

Regardless of their origin, the multivariate technique must be implemented on a computer. Through the development of sophisticated statistical packages, computer technology made the implementation step easier. All the programs used to generate the result in this project report are written in the following statistical software

$\mathrm{R}$ version 3.6.0

Microsoft Office Excel 2007

\section{REVIEW OF LITERATURE}

A literature review is a critical analysis of published sources on a particular topic, consequently, it certifies a theoretical framework and rationale for a research study. It can be useful to place our study in some sort of an overall perspective on the literature dealing with the problem of forecasting with vector autoregressive works. In this chapter, I try to display the overall scenario of forecasting of the inflation rate and interest rate of Bangladesh, previous work on these variables. 


\section{Measuring Co-Movement of Real Interest Rate and Inflation Rate: Using VEC Approach}

\subsection{VECTOR AUTOREGRESSIVE PROCESS}

There are many types of MTS models to choose from. First of all, there is a decision about linear and non-linear models (Casdagli, 1992), and then the specific type of model within these two categories. The main linear models are the Vector Autoregressive (VAR) process, Vector Moving Average (VMA) process, and Vector Autoregressive Moving Average (VARMA) process (Lutkepohl, 1993). Vector Auto-regression (VAR) is a powerful tool to analyze multivariate time series which are endogenous. Sim (1980) introduced the VAR model for describing the dynamic behavior ofeconomic and financial time series and for forecasting. It is found to exhibit greater predictive efficiency and accuracy than the large scale structural economic models. Since then, VAR models have been applied to various problems such as econometric analysis, climate forecasting, geophysics, medical analysis, and so on.

\subsection{SPECIFIC LITERATURE RELATED TO THIS STUDY}

The inflation prime, which can expect inflation investors increase the real risk-free returns, is inadequate. (Md. M Alam, K. A. Alam, and MD. G. S. Uddin, 2008). William J Crowder and Dennis L Hoffman (2007) identify that, under the unit root hypothesis, persistence in nominal interest rates and inflation is often modeled upon. A perfectly effective estimator is applied, which distinguishes the calculation of the long-term equilibrium relationship from the nuisance parameters. It discloses a long-term interest-to-inflation relation. It also finds however that the short-term interest rates may not even be good predictors of future inflation.

Some studies considering the data in the context of Bangladesh showed that the inflation and interest have no significant relationship. Analyzing data from 2002 to 2011 Emon Kalyan Chowdhury (2012) shows that the bank lending rates and the interest rates have no significant relation. Evans, in a study, Martin and Karen Lewis (1995) foundco-integrating the relationship between interest rate and post-war sample inflation, and using the DOLS estimator to estimate long run nominal interest rate response with related inflation.

From the above, we have noticed that there exists a relationship between the inflation rate and the interest rate from different research work done on the investigation of relationships.

\section{METHODOLOGY}

\subsection{DATA SOURCE AND VARIABLE DESCRIPTION}

In this study data from the source of secondary time series were used. It extracts these data from the official website of Bangladesh Bank and the World Bank and have only three variables from the year 1980 to 2016 . We listed "Real Interest Rate" and "Inflation Rate" for each year. Because of lack of data, we haven't used the data from recent few years. We will use RIR for "Real Interest Rate" and IR for "Inflation Rate".

\subsection{STUDY DESIGN AND METHODS}

We use the VAR model and Vector Error Correction Model (VECM) to quantifying the data. We will use dome plots to identify the data. Also, we will use ACF and PACF to identify the relationship between two variables. We will use several tests of hypothesis to justify the final results.

\subsection{ERROR CORRECTION MODEL (ECM)}

ECMs estimate the speed at which a dependent variable returns to symmetry after analteration of other variables. In the literature list, several methods are found to estimate a refined dynamic model. The mentionable ones are the Engel and Granger 2-step approach and the vector-based VECM. The 1st one estimates ECM in one step and 2nd one uses Johansen's method.

\subsection{VECM}

The Engle-Granger approach has a number of weaknesses. Mentionable, it is limited to only a single equation with one variable considered to be the dependent variable that is explained by another variable that is supposed to 
Md. Rasel Hossain, Ahsanul Haqu, Md. Abdullah Amir Hamja, and M. Shohel Rana

be weakly independent for the parameters of interest. Also, it also depends on pretesting the time series to check whether variables are I (0) or I (1) [21]. However, through the use of Johansen's procedure, such weaknesses can be addressed. Its use includes that pretesting is not necessary, there can be numerous co-integrating relationships, all variables are treated as endogenous and tests relating to the long run parameter are possible. The resulting model is called as a vector error correction model (VECM), as it adds error correction features to a multi-factor model known as vector auto-regression (VAR). The testing procedure is described as follows:

Step one: Estimate an unrestricted VAR equation involving non-stationary variables

Step two: Test for co-integration using the Johansen test

Step three: Form and analyze the VECM

\section{Result and Discussion}

Inflation and interest rate are two important economic variables of the Bangladesh economy. In this section, we check the stationary of the data, investigated the relationship between the variables, and made forecasts using an appropriate vector autoregressive model (VAR).

\subsection{THE PLOT OF THE DATA}

We have two variables in our study. The plots of these two variables found by using the R-program. From these graphs, we are able to understand the pattern of the data.

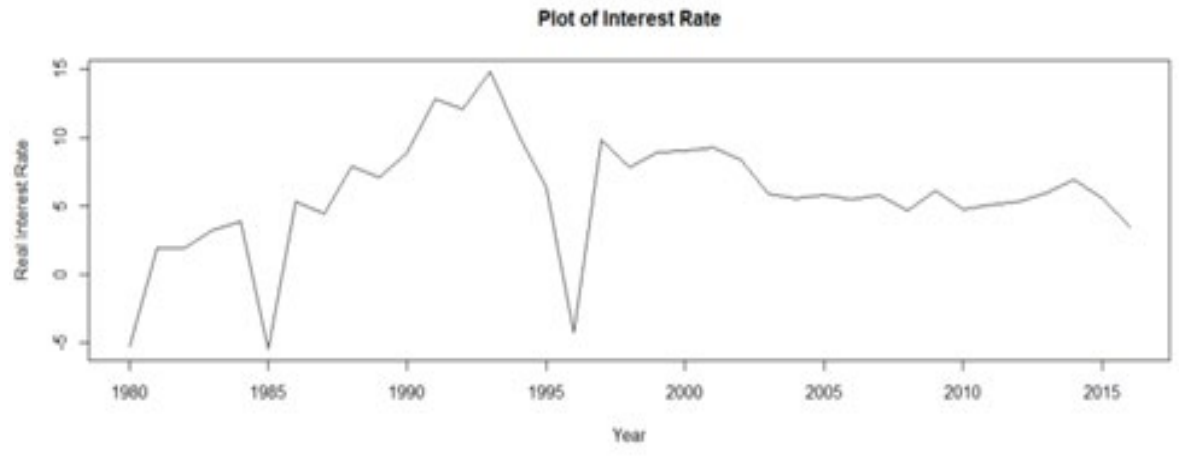

Figure 1: Plot of Real Interest Rate (RIR)

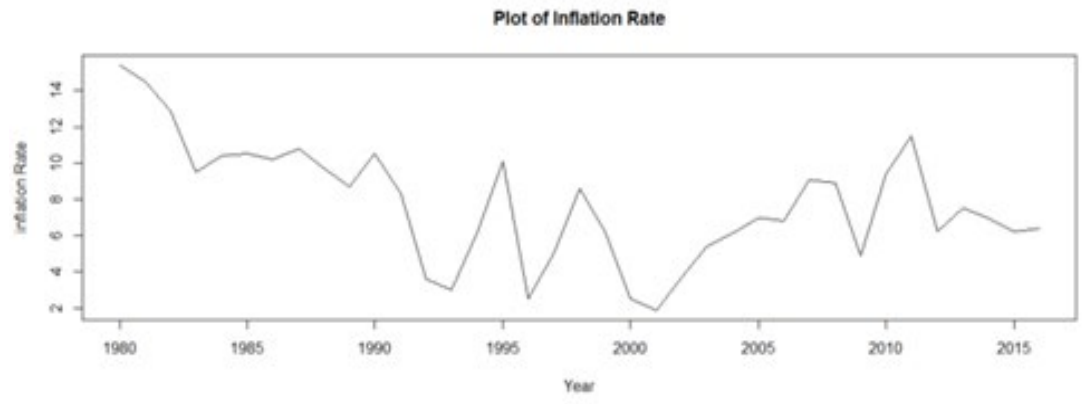

Figure 2: Plot of Inflation Rate (IR)

From Fig 1 of the interest rate, we see that the data is non-stationary. It has some trend. The graph in Fig 2also shows that the inflation rate is also non-stationary and it has also variations.

\subsection{ACF and PACF test for variables}

The ACF and PACF plot of the interest rate is shown in the figures below. From these plots also, we can see the stationarity or non-stationarity of real interest rate: 
Measuring Co-Movement of Real Interest Rate and Inflation Rate: Using VEC Approach

ACF of Real Interest Rate

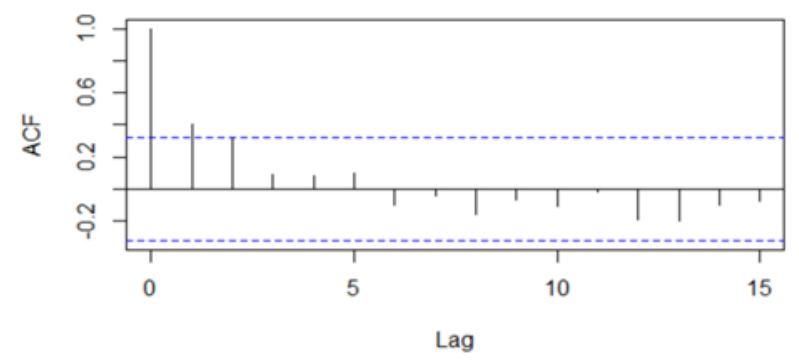

Figure 3: ACF of Real Interest Rate (RIR)

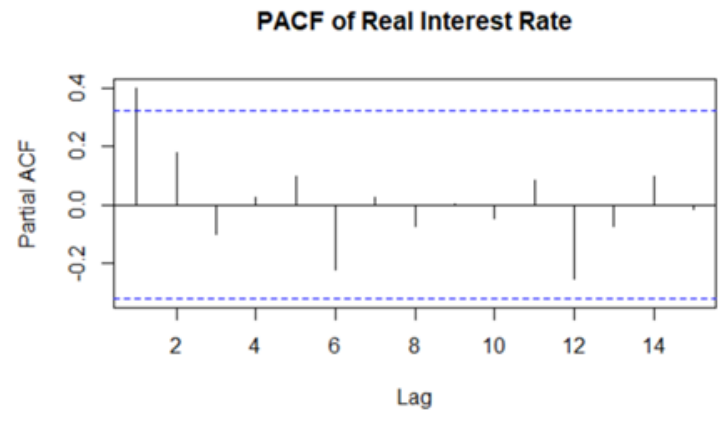

Figure 4: PACF of Real Interest Rate (RIR)

Examining the above autocorrelation in Fig 3 and partial autocorrelation plots in Fig 4 for the time series of annual real interest rates indicates that there is autocorrelation in the data. That is the autocorrelation exists in the data of real interest rate.

Now, we examine the ACF and PACF of the inflation rate. The ACF and PACF are given below for the data inflation rate:

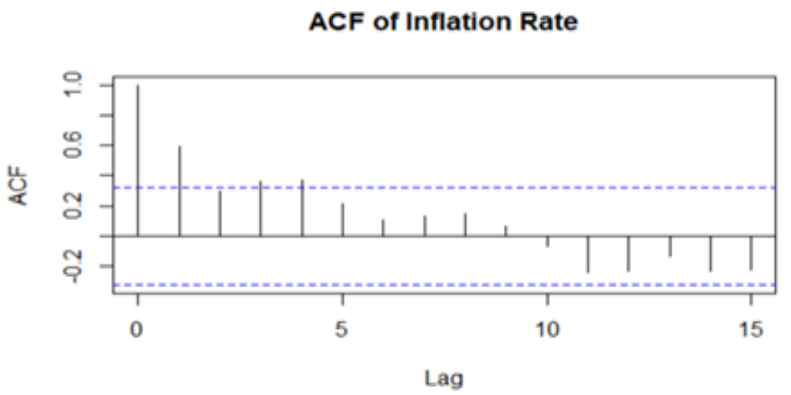

Figure 5: ACF of Inflation Rate (IR)

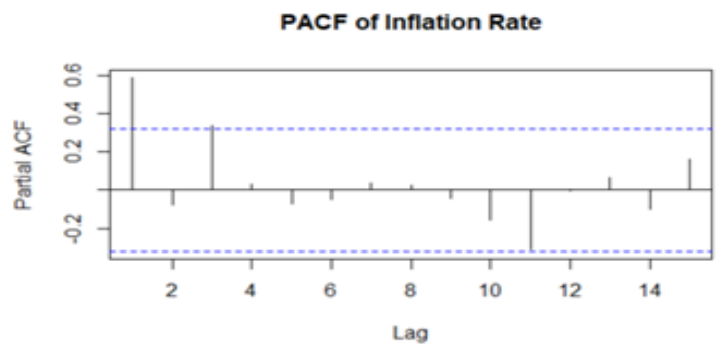

Figure 6: PACF of Inflation Rate (IR) 
Md. Rasel Hossain, Ahsanul Haqu, Md. Abdullah Amir Hamja, and M. Shohel Rana

From the above Fig 5of autocorrelation and Fig6ofpartial autocorrelation plots for the time series of the annual inflation rate of Bangladesh suggest that the ACF and PACF present in this series are significant. That means there is autocorrelation in the time series data of the annual inflation rate of Bangladesh.

\subsection{UNIT ROOT TEST}

Before we apply the different techniques of multivariate time series analysis, we need to check for stationary of each variable under study since many of the methods assume that the data is stationary with respect to the mean and variance. We have used ADF and KPSS tests for unit root test in this study and for checking the unit root of the data. We know the null hypothesis is following

Ho: the time series is non-stationary or it has a unit root.

H1: the time series is not stationary.

The unit root test results for the inflation rate and the interest rates are shown below:

Table 1: The unit root test results for the Inflation Rate and Real Interest Rates

\begin{tabular}{|l|c|c|c|c|c|}
\hline Variable & \multicolumn{2}{|c|}{ Test statistics } & \multicolumn{2}{c|}{ P-Value } & Decision \\
\hline & ADF & KPSS & ADF & KPSS & \\
\hline Interest Rate & -2.3226 & 0.2932 & 0.4474 & 0.1 & Non-stationary \\
\hline Inflation Rate & -1.7454 & 0.69911 & 0.6725 & 0.01363 & Non-stationary \\
\hline
\end{tabular}

From the above table and the values of test statistics and p-value for ADF and KPSS test, we accept the null hypothesis. That is both the variables are non-stationary. We have compared the p-value with a significant level of 0.05 .

\subsection{MODEL SELECTION}

We know from the model selection criteria if the variables are non-stationary at level but it becomes stationary at the same integrated order also having co-integration among the variables that means long-run relationship exists. In which case we may proceed to apply the Vector Error Correction (VEC) Model. So, in this case, we have decided to use the VEC Model,

\subsection{VEC MODEL ORDER SELECTION}

Table 2: VEC Model order selection

\begin{tabular}{|l|c|c|}
\hline Lag & FPE & Optimum Order \\
\hline 0 & 88.7284 & \\
\hline 1 & 83.922 & \\
\hline 2 & 74.0542 & \\
\hline 3 & $64.376^{*}$ & $64.376^{*}$ \\
\hline 4 & 84.6978 & \\
\hline 5 & 99.9201 & \\
\hline 6 & 104.954 & \\
\hline 7 & 149.736 & \\
\hline 8 & 182.989 & \\
\hline 9 & 177.121 & \\
\hline 10 & 141.697 & \\
\hline
\end{tabular}

From Table 2, we will use this optimal value 64.376 in the VEC model. 
Measuring Co-Movement of Real Interest Rate and Inflation Rate: Using VEC Approach

Table 3: VEC Model of interest rates

\begin{tabular}{|c|c|c|c|c|c|c|}
\hline \multirow[b]{2}{*}{ _ce1* } & Coef. & Std.Err. & $\mathrm{z}$ & ${ }^{*} \mathrm{P}>\mathrm{Z}$ & \multicolumn{2}{|c|}{ [95\% $\quad$ Conf. Interval] } \\
\hline & & & & & & \\
\hline L1. & -.5054112 & .2433272 & -2.08 & 0.038 & -.9823237 & -.0284987 \\
\hline \multicolumn{7}{|l|}{ RIR } \\
\hline LD. & .0353875 & .2608094 & 0.14 & 0.892 & -.4757895 & .5465646 \\
\hline L2D. & .2402316 & .1890877 & 1.27 & 0.204 & -.1303735 & .6108367 \\
\hline \multicolumn{7}{|l|}{ IR } \\
\hline LD. & -.309081 & .2755313 & -1.12 & 0.262 & -.8491125 & .2309505 \\
\hline L2D. & .2096575 & .2727726 & 0.77 & 0.442 & -.324967 & .7442821 \\
\hline _cons & .1373703 & .6347859 & 0.22 & 0.829 & -1.106787 & 1.381528 \\
\hline
\end{tabular}

Table 4: VEC Model of Inflation Rat

\begin{tabular}{|c|c|c|c|c|c|c|}
\hline & Coef. & Std.Err. & $\mathrm{z}$ & ${ }^{*} \mathrm{P}>\mathrm{Z}$ & \multicolumn{2}{|c|}{ Conf. Interval] } \\
\hline \multicolumn{7}{|l|}{ _ce1* } \\
\hline L1. & -.4227146 & .1394103 & -3.03 & 0.002 & -.6959537 & -.1494755 \\
\hline \multicolumn{7}{|l|}{ RIR } \\
\hline LD. & 1662107 & .1494264 & 1.11 & 0.266 & -.1266597 & .4590812 \\
\hline L2D. & .0637291 & .1083347 & 0.59 & 0.556 & -.1486029 & .276 \\
\hline \multicolumn{7}{|l|}{ IR } \\
\hline LD. & .0360695 & .1578611 & 0.23 & 0.819 & -.2733325 & .3454716 \\
\hline L2D. & -.4630647 & .1562806 & -2.96 & 0.003 & -.769369 & -.1567604 \\
\hline _cons & -.1642446 & .3636901 & -0.45 & 0.652 & -.8770641 & .5485748 \\
\hline
\end{tabular}

From the model fitting output in Table 3 and Table 4, we get_ce ${ }^{*}$ means one co-integrated equation. We also have the error correction term or long run speed of adjustment ( -0.4227146$)$ which is negative that indicating longrun causality and the P-value of EC term is 0.038 which is less than 0.05 . So, they may reject the null hypothesis. So, there is a long run causality between the variables.

\subsection{MODEL FITTING}

$\mathrm{D}(\mathrm{RIR})=-0.54112 .3813593041 *(\mathrm{RIR}(-1)+1.268138 * \operatorname{IR}(-1)--15.27406+0.1356833603 * \mathrm{D}(\mathrm{RIR}(-1))$ $+0 . .24023165470540543 * \mathrm{D}(\mathrm{RIR}(-2))-0.1311689931 * \mathrm{D}(\mathrm{RIR}(-3))+-.309081 \mathrm{D}(\operatorname{IR}(-1))+.2096575 * \mathrm{D}(\operatorname{IR}(-2))-$ $0.03089980939 * \mathrm{D}(\operatorname{IR}(-3))-0.286900269$

$\mathrm{D}(\mathrm{IR})=-.4227146 *(\mathrm{RIR}(-1)+1.268138 \mathrm{IR}(-1)--15.27406)+.1662107 * \mathrm{D}(\mathrm{RIR}(-1))+.0637291 * \mathrm{D}(\mathrm{RIR}(-2))$ $+0.03428728671 * \mathrm{D}(\mathrm{RIR}(-3))+.0360695^{*} \mathrm{D}(\mathrm{IR}(-1)-.4630647 \mathrm{D}(\mathrm{IR}(-2))-0.03724786771 * \mathrm{D}(\mathrm{IR}(-3))-.1642446$

Adjustment parameters

\begin{tabular}{|l|c|c|c|}
\hline Equation & Parameters & chi2 & P>chi2 \\
\hline RIR & 1 & 4.314281 & 0.0378 \\
\hline IR & 1 & 9.194008 & 0.0024 \\
\hline
\end{tabular}

\subsection{CHECKING SHORT RUN CAUSALITY}

For the first time, we think Real Interest Rate (D_RIR) is the dependent variable, and lags of RIR also lag of IR as an independent variable. It is clear that no lag variable is significant at the chosen level of significance. It is the indication of having no short-run causality. But in case of Real interest dependent variable and other is independent variable at which only **2D is significant.

So, we may say that a long run relationship exists between RIR and IR. At the same time, there exists a long-run causality. 
Md. Rasel Hossain, Ahsanul Haqu, Md. Abdullah Amir Hamja, and M. Shohel Rana

\subsection{TEST OF LINEAR HYPOTHESIS}

Test Real Interest Rate (RIR)

test ([RIR]: LD.IR L2D.IR)

(1) $[$ RIR]LD.IR $=0$

(2) $[\mathrm{RIR}] \mathrm{L} 2 \mathrm{D} . \mathrm{IR}=0$

$\operatorname{chi} 2(2)=2.53$

Prob $>$ chi $2=0.2828$

The null hypothesis is accepted which means short-run causality doesn't run from Inflation Rate (IR) to Real Interest Rate (RIR).

Test Interest Rate (IR)

test ([IR]: LD.RIR L2D.RIR)

(1) $[$ IR]LD.RIR $=0$

(2) $[$ IR]L2D.RIR $=0$

$\operatorname{chi} 2(2)=1.27$

Prob $>$ chi $2=0.5300$

The null hypothesis is accepted which means short-run causality doesn't run from Real Interest Rate (RIR) to Inflation Rate (IR).

\subsection{DIAGNOSTIC CHECKING}

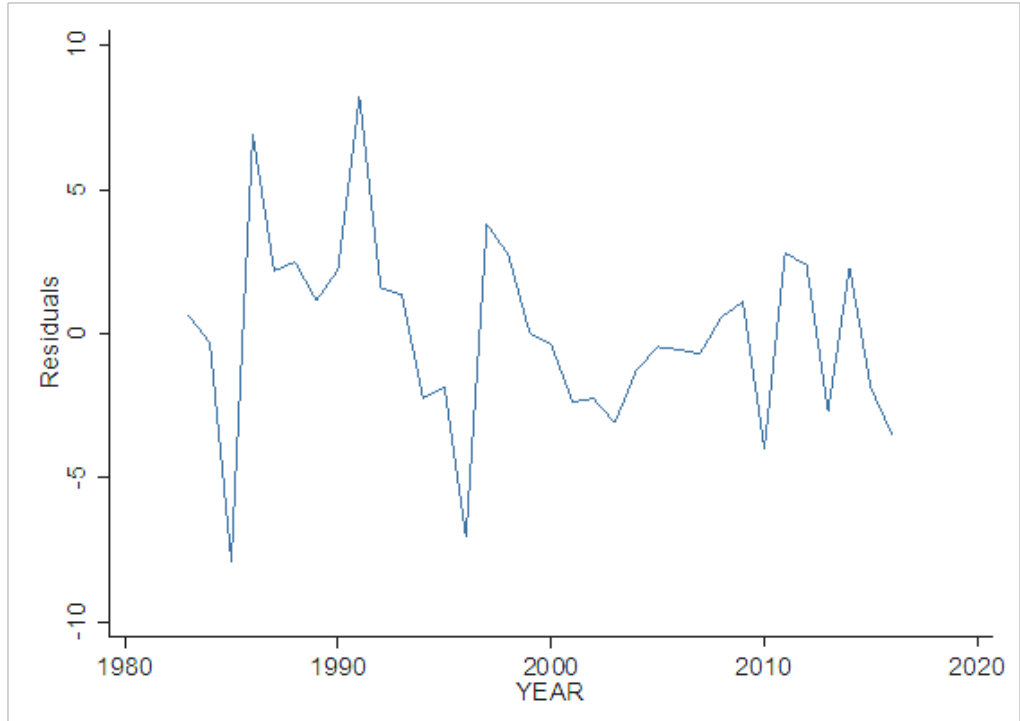

Figure 7: Diagnostic Checking for Residuals

The Fig 7 residual line plot indicates that the extracting residuals series from the VEC model is white noise which means residuals series is stationary. 
Measuring Co-Movement of Real Interest Rate and Inflation Rate: Using VEC Approach

\subsection{AUTOCORRELATION TEST OF RESIDUALS}

Lagrange-multiplier test

\begin{tabular}{|c|c|c|c|c|}
\hline Lag & & & $\mathrm{df}$ & Prob $>$ chi \\
\hline 1 & 1.3526 & 4 & 0.8 & 39 \\
\hline
\end{tabular}

H0: there is no autocorrelation at lag order

Since P-value $>0.05$, we may accept the null hypothesis (H0) at 5\% level of significance. It means residuals are not auto-correlated.

\subsection{UNIT ROOT TEST OF RESIDUALS}

\section{Augmented Dickey-Fuller Test}

Null Hypothesis: There is a unit root in residual

\begin{tabular}{|l|c|c|c|}
\hline ADF Test Statistic & 5.409455 & $1 \%$ Critical Value* & -3.6422 \\
\hline & & $5 \%$ Critical Value & -2.9527 \\
\hline & & $10 \%$ Critical Value & -2.6148 \\
\hline
\end{tabular}

*MacKinnon critical values for rejection of the null hypothesis of a unit root.

Null is rejected. So, the residual series is stationary.

\subsection{NORMALITY TEST OF RESIDUALS}

H_0: The residuals are normally distributed.

Jarque-Bera test

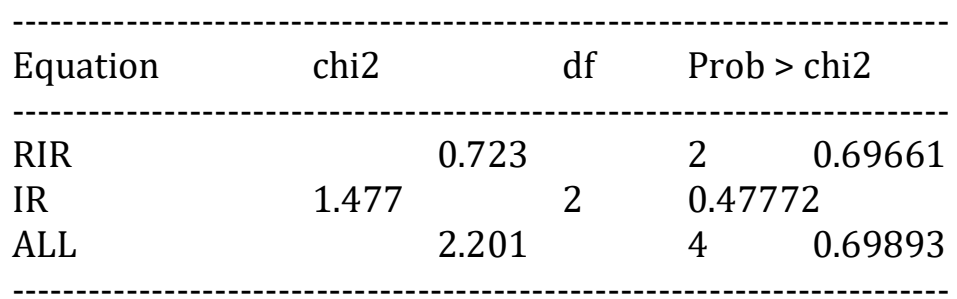

We observe that the overall JB P-value is $0.69893(>0.05)$ which means residuals normally distributed.

\subsection{PORTMANTEAU TEST FOR WHITE NOISE}

H0: The residuals are white noise

\begin{tabular}{|l|l|l|}
\hline Portmanteau (Q) & Portmanteau (Q) & Comment \\
\hline Prob $>$ chi2(15) & 0.9582 & H0: accepted \\
\hline
\end{tabular}

The null hypothesis accepted means residuals are stationary. So, we may accept that our model selection and model building was correct.

\section{CONCLUSION AND RECOMMENDATION}

Nowadays, pattern and movement analysis of economic variables is a very important task for any country. As a developing country, the current study is indispensable for the Bangladesh economy to reveal future behavior. This research involves the analysis of Real Interest Rate (RIR) and Inflation Rate (IR) during time period1980 to 2016. 
Md. Rasel Hossain, Ahsanul Haqu, Md. Abdullah Amir Hamja, and M. Shohel Rana

These variables were stationary at levels and it was confirmed by several unit root testing approaches as well as traditional graphical approaches. Appropriate order (i.e. Lag length) of the VEC model was chosen using Final Prediction Error (FPE) criteria and it was found that this order is 3. The diagnostic checking of VEC Model (3) divulged that the residuals were stationary, not auto-correlated and, approximately normally distributed. The longrun relationship has been justified by the Johansen cointegration test. VEC models exhibit remarkable features that are nothing but the long-run significant causal relationship between variables, on the contrary, there is no short-run causal relationship found. It indicates that the long run RIR and IR will move to together in the future.

\section{SOURCES OF FUNDING}

None.

\section{CONFLICT OF INTEREST}

None.

\section{ACKNOWLEDGMENT}

None.

\section{REFERENCES}

[1] Casdagli M., Eubank S., editors (1992). "Nonlinear modeling and forecasting”. Redwood City: Addison-Wesley.

[2] H. Lütkepohl (1993). "Introduction to multiple time series analysis". Springer-Verlag. Berlin And New York.

[3] Sims, C.A. (1980). "Macroeconomics and Reality" Econometrica. 48, 1-48.

[4] Salah Uddin, Md. M. Alam \& Alam, K. A. (2008). "An empirical evidence of Fisher effect in Bangladesh: A timeseries approach". ASA University Review, Vol. 2 No. 1, pp. 1-8.

[5] William, J. C. \& Dennis, L. Hoffman (2007). "Long run relationship between interest rates and inflation". Journal of Money, Credit and Banking, Vol. 28, No.1, pp.102-118.

[6] Emon Kalyan Chowdhury (2012). "Impact of Inflation on Bank Lending Rates in Bangladesh". Journal of Politics \& Governance, Vol. 1, No. 1, Jan-March 2012.

[7] Evans, Martin \& Karen, Lewis (1995). "Do expected shifts in inflation affect estimates of the long run Fisher relation?" Journal of Finance, Vol. 50, pp. 225-53.

[8] Liu, Olin, and Olumuyiwa, S. Adedeji, 2000. "Determinants of Inflation in the Islamic Republic of Iran - A Macroeconomic Analysis". IMF Working Paper No. 00/127, International Monetary Fund, Washington.

[9] Ubide, Angel (1997). "Determinants of inflation in Mozambique", IMF Working Paper WP/97/145: International Monetary Fund.

[10] Leheyda, Nina (2005). "Determinants of inflation in Ukraine: A cointegration approach. Mimeo". University of Mannheim, Mannheim: Centre for Doctoral Studies in Economics and Management (CDSEM).

[11] Khan, M.S. \& Axel, Schimmelpfennig (2006). “Inflation in Pakistan: Money or Wheat?". IMF Working Paper WP/06/60, International Monetary Fund: Middle East and Central Asia Department.

[12] Taslim, M. A. (1982). "Inflation in Bangladesh: A reexamination of the structuralist -monetarist Controversy". The Bangladesh Development Studies, Vol. 10 (1), pp.23-52.

[13] Anderson, T. W. (1984). "An Introduction to Multivariate Statistical Analysis". 2nd ed., New York: John Wiley and Sons Inc.

[14] Akaike H (1969). "Fitting autoregressive model for Prediction". Ann Ins Stat Math 21:243-247.

[15] Brockwell P. J. and R. A. Davis (1996). "Introduction to Time Series and Forecasting". Springer, New York.

[16] Gujrati, D. (2002). "Basic Econometric". 4th Edition, McGraw-Hill.

[17] Elliott, G., Rothenberg, T. J. \& Stock, J. H. (1996). "Efficient tests for an autoregressive unit root". Econometrica, Vol. 64, No. 4, pp.813-836.

[18] Fredric, S. M. (1992). "Is the Fisher effect for real? A reexamination of the relationship between inflation and interest rates". Journal of Monetary Economics, Vol. 30, pp. 195-215. 
Measuring Co-Movement of Real Interest Rate and Inflation Rate: Using VEC Approach

[19] Kwong, Mary, Big man, David \& Taya, Teizo (2002). "Floating exchange rates and the state of world trade and payments". Beard Books.

[20] Rose, Andrew (1998). “Is the interest rate for real?”. Journal of Finance, Vol.43, pp.1092-112.

[21] https://en.wikipedia.org/wiki/Error_correction_model. 